\title{
Substance $P$ immunoreactivity in the lumbar spinal cord of the turtle Trachemys dorbigni following peripheral nerve injury
}

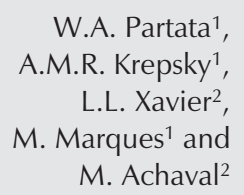

\author{
Departamentos de ${ }^{1}$ Fisiologia and ${ }^{2}$ Ciências Morfológicas, \\ Instituto de Ciências Básicas da Saúde, \\ Universidade Federal do Rio Grande do Sul, Porto Alegre, \\ RS, Brasil
}

Correspondence

W.A. Partata

Departamento de Fisiologia

ICBS, UFRGS

Rua Sarmento Leite, 500

90050-170 Porto Alegre, RS

Brasil

Fax: +55-51-316-3166

E-mail: partataw@excite.com

Research supported by CAPES, CNPq and FINEP (No. 66.91.0509.00).

Received September 25, 2001 Accepted January 6, 2003

\section{Abstract}

Immunoreactive substance $\mathrm{P}$ was investigated in turtle lumbar spinal cord after sciatic nerve transection. In control animals immunoreactive fibers were densest in synaptic field Ia, where the longest axons invaded synaptic field III. Positive neuronal bodies were identified in the lateral column of the dorsal horn and substance P immunoreactive varicosities were observed in the ventral horn, in close relationship with presumed motoneurons. Other varicosities appeared in the lateral and anterior funiculi. After axotomy, substance P immunoreactive fibers were reduced slightly on the side of the lesion, which was located in long fibers that invaded synaptic field III and in the varicosities of the lateral and anterior funiculus. The changes were observed at 7 days after axonal injury and persisted at 15, 30, 60 and 90 days after the lesion. These findings show that turtles should be considered as a model to study the role of substance $\mathrm{P}$ in peripheral axonal injury, since the distribution and temporal changes of substance $\mathrm{P}$ were similar to those found in mammals.

Peripheral nerve injury may result in significant changes in neuropeptide production and the development of neuropathic pain behavior (1). In rats, peripheral nerve sectioning leads to a marked quantitative decrease in the nerve of substance $P$, a peptide of 11 amino acids that is present in small primary afferents and plays an important role in pain sensation $(2,3)$.

The chemical structure of substance $P$ is highly conserved in non-mammalian species, and is also found in turtles, animals considered phylogenetically related to the extinct theropsids from which mammals arose (4). Previous studies demonstrated substance
P immunoreactivity in the turtle central nervous system $(5,6)$; however, the effects of peripheral axotomy on substance $P$ distribution have not been studied. Therefore, the aim of this study was to determine the effects of sciatic nerve transection on substance $P$ immunoreactive fibers in the lumbar spinal cord of the turtle Trachemys dorbigni.

Under ether-induced anesthesia (7), the right sciatic nerve was exposed and transected approximately $5 \mathrm{~mm}$ distal to the sciatic notch. In this nerve transection, a 2-mm segment of the nerve was removed to ensure that the transection was complete. Groups of three turtles of both sexes, weighing 300-400 
g, were sacrificed $7,15,30,60$ and 90 days later. On the final day of the experiment, both operated and control turtles were anesthetized $(25 \mathrm{mg} / \mathrm{kg}$ Thionembutal, intraperitoneally) and perfused through the heart with cold saline solution followed by $4 \%$ paraformaldehyde in $0.1 \mathrm{M}$ sodium phosphate buffer, $\mathrm{pH}$ 7.4. The lumbar spinal cord was quickly dissected out, immersed in the same fixative for $2 \mathrm{~h}$ and then cryoprotected in 15 and $30 \%$ sucrose solutions in phosphate buffer at $4^{\circ} \mathrm{C}$. Coronal serial sections $(50 \mu \mathrm{m})$ were obtained with a cryostat (Leitz) and collected in cold phosphate-buffered saline (PBS). The sections were then treated with $3 \%$ hydrogen peroxide in $10 \%$ methanol for 30 min, washed with PBS for a further 30 min and incubated for $30 \mathrm{~min}$ in 3\% normal goat serum in PBS containing $0.4 \%$ Triton X-100 (PBS-T). A polyclonal antibody to rabbit substance P (a gift from Dr. Joaquín Del Río, Department of Pharmacology, Navarra University, Spain), whose specificity has been described in a previous report (8), diluted 1:800 in PBS-T, was applied to the sections which were incubated overnight with gentle shaking at $4^{\circ} \mathrm{C}$. The primary antibody was then removed and the sections were washed in PBS-T for $30 \mathrm{~min}$ and were then immersed in secondary antibody (antiIgG; Sigma, St. Louis, MO, USA), diluted 1:50 in PBS- $\mathrm{T}$, for $2 \mathrm{~h}$ at room temperature with gentle shaking. After washing with PBS$\mathrm{T}$ for $30 \mathrm{~min}$, a soluble complex of horseradish peroxidase rabbit anti-horseradish peroxidase (Sigma) diluted 1:500 was applied for $2 \mathrm{~h}$ at room temperature. The samples were then washed in PBS, incubated in a solution of 3,3-diaminobenzidine tetrahydrochloride (60 mg/100 ml; Sigma) and 0.005\% $(\mathrm{v} / \mathrm{v})$ hydrogen peroxide in PBS. The sections were washed, mounted onto gelatinized slides and coverslipped with Entellan. Specific immunostaining was abolished when the primary antibody was omitted in the staining sequence. The intact contralateral spinal segments were used as control. Sec- tions were examined and photographed with a Nikon Optiphot-2 microscope equipped with a Nikon FX-3 5DX camera.

A Nikon Eclipse E 600 (400X) microscope coupled to a pro-series high performance CCD camera and image Pro Plus software 4.1 (Media Cybernetics, Silver Spring, MD, USA) was used to measure the intensity of the reaction product of substance $P$ immunohistochemistry (semiquantitative analysis). Synaptic subfield Ia was delimited, the obtained images were digitized and converted to 8-bit gray scale (0-255 gray levels) and the regional absorbance was measured. Obvious blood vessels and other artifacts were not considered. The readings were performed on the left and right side of the lumbar spinal cord and at least five readings were obtained. Background staining from a non-reactive tissue was determined and used to correct the absorbance measurements. All lighting conditions and magnifications were held constant.

During the analysis, the investigator was unaware of the experimental groups from which the slices were obtained. The absorbance (A) measurement formula used was the following:

$A_{(x, y)}=100-\left\{\left[\left(\right.\right.\right.$ background $_{(x, y)}-$ black $)-$ (intensity $_{(\mathrm{x}, \mathrm{y})}-$ black)/(incident - black)]/255\} $\mathrm{x} 100$

where background $\mathrm{x}_{(\mathrm{x}, \mathrm{y})}$ is the background intensity at $\operatorname{pixel}_{(\mathrm{x}, \mathrm{y})}$, and intensity $\mathrm{x}_{(\mathrm{x}, \mathrm{y})}$ is the intensity at $\operatorname{pixel}_{(\mathrm{x}, \mathrm{y})}$, black is the intensity generated when no light goes through the material, and incident is the intensity of the incident light. The results reported represent the mean of all pixels in the selected area on a $100 \%$ scale. In the present study, the thickness of the sections $(50 \mu \mathrm{m})$ used did not lead to immunohistochemical over-reactions or saturation of absorbance. Other anatomical areas located in the lumbar spinal cord could not be selected because these areas did not present well-defined limits. The animals with different survival times could not be 
compared because the immunohistochemistry was performed on different days. Statistical analysis was carried out using the paired Student $t$-test. The mean diameter of immunostained cell bodies was measured semiautomatically using the same software employed to determine absorbance.

Commonly accepted cytoarchitectonic divisions derived from investigations on mammals proved inadequate when exploring the dorsal gray of the turtle. Thus, for the dorsal horn description we followed the pattern described for turtles by Trujillo-Cenóz et al. (9), which suggests the occurrence of four axonal populations in the turtle dorsal horn. According to these investigators, synaptic field Ia is probably analogous to Lissauer's tract in mammals, while synaptic field II is perhaps homologous to the substantia gelatinosa.

Substance P immunoreactivity was detected in varicose fibers and dot-like structures without intervaricose connections. These structures (termed fibers below) are believed to be mostly nerve terminals according to Ljungdahl et al. (10). They appear as distinct dark brown particles and/or "strings of beads". Control sections did not present immunoreactivity.

In control animals, substance P immunoreactivity was found in the dorsal and ventral horns of the lumbar spinal cord, which was higher in gray matter than in white matter. A similar density of fiber clusters was observed on both sides of the spinal cord. The dorsal horn developed more substance $P$ immunoreactivity than the ventral horn. In the dorsal horn, dense immunoreactive fibers were identified in synaptic field Ia (Figure 1, top, A and B), with the longest axons invading synaptic field III, which exhibited some positive fibers. Furthermore, some long positive fibers were detected crossing the midline of the spinal cord and entering the contralateral side (Figure 1, top, D). The synaptic fields Ib and II were unstained. A dense collection of positive fibers was iden- tified in the ventromedial dorsal horn. Immunostaining of neuronal cell bodies $(20.08$ $\pm 0.72 \mu \mathrm{m}$ in diameter) occurred in the lateral column of the dorsal horn (Figure 1, top, C). Substance P immunoreactive varicosities were scattered in the ventral horn and some of them appeared to abut motoneurons, which showed no immunoreactivity (Figure 1, top, E). Other positive varicosities were found in the lateral and dorsal funiculi (data not shown). These data agree with previous investigations that reported the presence of substance $P$ in the nervous system of the turtle Chrysemys picta picta (5). However, our results seem to be higher than those found in a previous study in the dorsal horn of Chrysemys d'orbigny (6). These investigators only reported the presence of substance $\mathrm{P}$ immunoreactivity in synaptic field Ia, which invaded synaptic field III, and in the ventral horn limit. There is no report of positive immunoreactive fibers in the lateral and dorsal funiculi. Nevertheless, it is known that this neuropeptide has been detected in these regions in mammals $(11,12)$, frogs $(13,14)$, and domestic fowl (15). In addition, these studies demonstrated the presence of substance $\mathrm{P}$ immunoreactivity in the ventral horn of these animals, as found in turtles. The same studies do not refer to the presence of substance $P$ immunoreactivity in cell bodies of the spinal cord, except for frogs (14). It is possible that the presence of immunoreactive cell bodies in Trachemys dorbigni spinal cord resulted from the different postperfusion immersion procedure employed. The duration of this step has a greater effect on perinuclear immunoreactivity than colchicine treatment (5). In the present study the postperfusion immersion time was shorter than that used by Reiner et al. (5). Further studies about this question are necessary.

Transection of the sciatic nerve resulted in small changes in the pattern of substance $\mathrm{P}$ distribution in the turtle dorsal horn. These modifications were located on the same side as the lesion. They consisted of a small 
decrease in the long immunoreactive fibers that penetrated synaptic field III (Figure 1, bottom) and in the varicosities of the lateral and anterior funiculi. These changes were already present by 7 days after nerve transection (Figure 1, bottom, A), and persisted
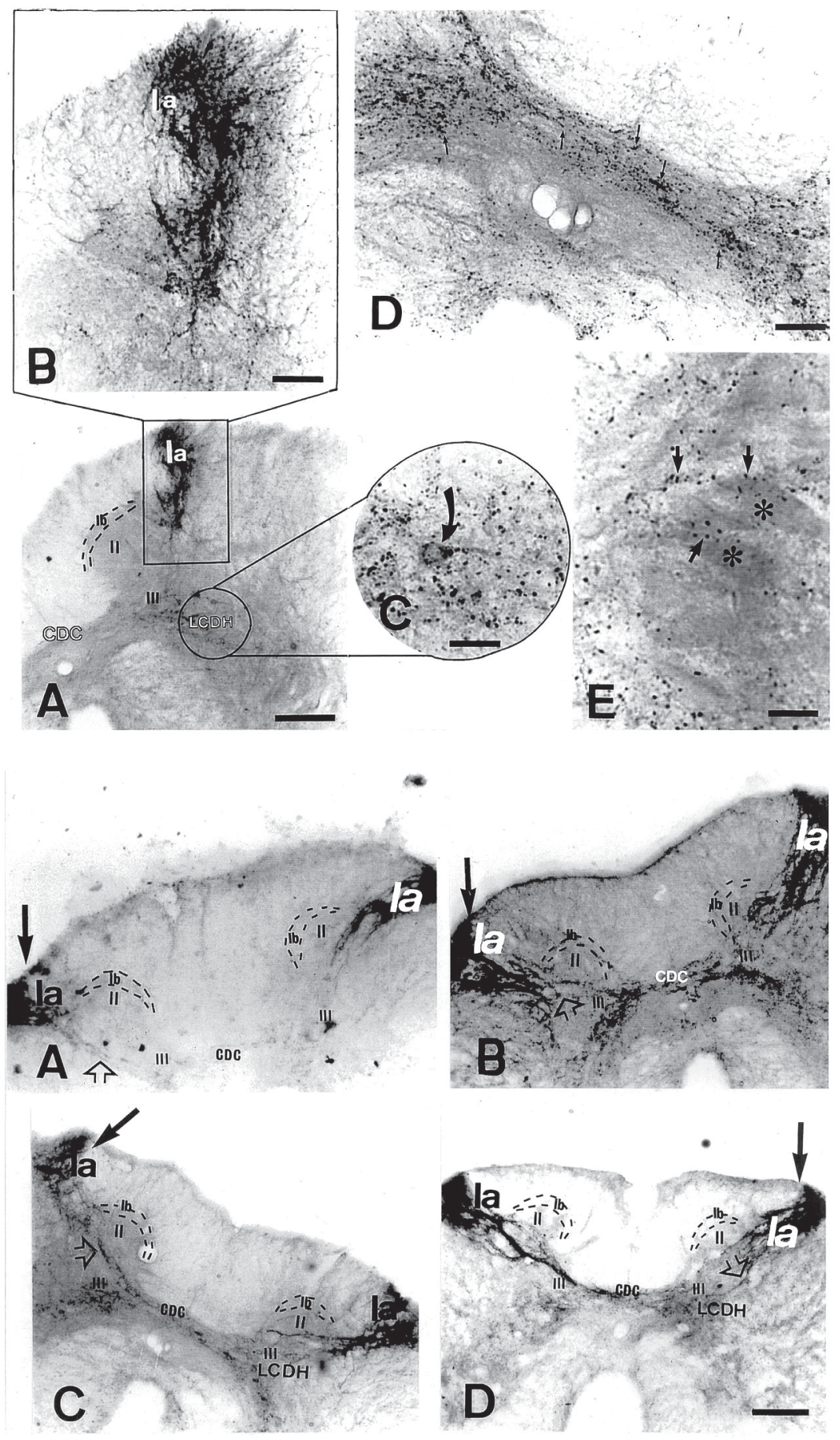

unchanged at 15, 30, 60 and 90 days following the lesion (Figure 1, bottom, B-D). The synaptic field Ia showed the same staining pattern on the ipsilateral and contralateral side of the spinal cord (Figure 1, bottom, AD), which was confirmed by optical densitometry (Figure 2).

In mammals, peripheral nerve section also leads to a marked quantitative decrease of substance $\mathrm{P}$ in the dorsal horn $(11,16)$. Data from quantitative immunoelectron microscopy and receptor binding experiments showed that this change resulted from the degeneration of dorsal root afferents $(17,18)$. In turtles, the dorsal root terminals were found in synaptic fields Ia, Ib, II and III, with some long fibers projecting to the contralateral dorsal horn (9). These findings support the view that the changes described here correspond to degeneration of dorsal root afferents located in synaptic field III. However, there is a striking similarity between the immunoreactive patterns of the ipsilateral and contralateral synaptic fields Ia. However, a recent study has revealed that the synaptic arrays in the peripheral synaptic fields (Ia, Ib and II) are complex, whereas they are simple in deeper regions of the

Figure 1. Top, Distribution of substance $\mathrm{P}$ immunoreactivity in the spinal cord of control turtles. $A$, Intense immunoreactive fibers in synaptic field la. From this area the positive fibers project to deeper dorsal horn regions until they reach synaptic field III. Note the lack of reactivity in synaptic fields II and Ib. However, observe the presence of immuneroactivity in the lateral column of the dorsal horn (LCDH). CDC: dorsal commissure. Scale bar: $300 \mu \mathrm{m}$. B, High magnification of the region analyzed in $A$. Scale bar: $100 \mu \mathrm{m}$. C, High magnification of the encircled region shown in $A$. Immunoreactive neuron of the LCDH (arrow). Scale bar: $50 \mu \mathrm{m} . \mathrm{D}$, Immunoreactive fibers (arrows) in the dorsal commissure. Scale bar: $100 \mu \mathrm{m}$. E, Immunoreactive fibers (arrows) in the ventral horn. Note that these fibers appear to abut motoneurons (asterisks). Scale bar: $50 \mu \mathrm{m}$. Bottom, Substance P immunoreactivity in the spinal cord of the turtles 7 (A), 15 (B), 30 (C) and 90 (D) days following peripheral nerve transection. The arrows indicate the side of the lesion. Note the decrease in substance $\mathrm{P}$ immunoreactivity in the long fibers on the lesion side (open arrow). Scale bar: 300 $\mu \mathrm{m}$. 


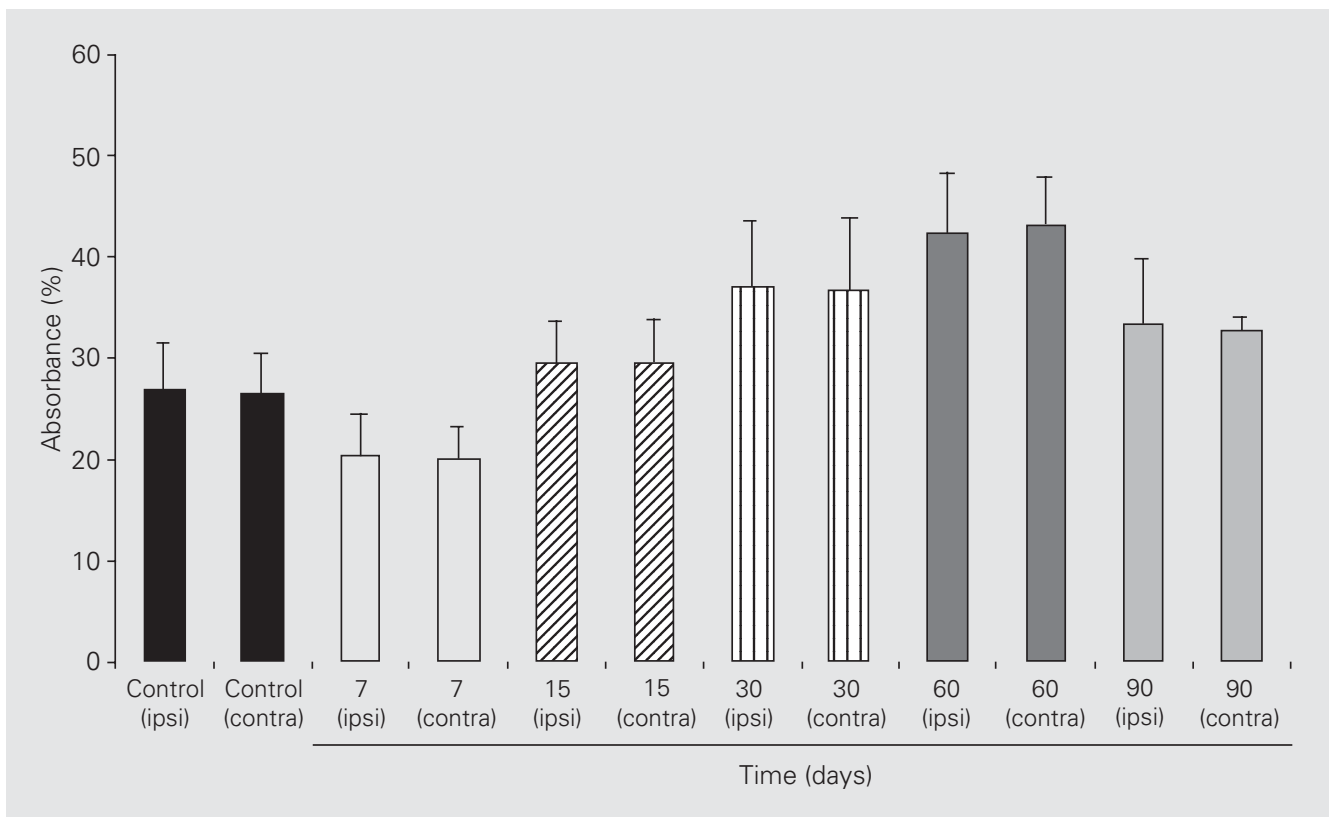

dorsal horn (synaptic field III), consisting of typical synaptic boutons contacting either dendrites or neuronal somata (9). Therefore, it seems reasonable to speculate on whether the initial changes following deafferentation begin in the more simple synaptic arrays and extend to the complex synaptic field later, after 90 days. If this occurs, the pattern of change in the turtle is slower than in the rat, since in the latter the density of substance $\mathrm{P}$ immunoreactivity showed a significant reduction at 4 days, which reached almost complete terminal restoration at 2 months following deafferentation (19). Nevertheless, if this is true, this slow rate of change in the turtle may permit researchers to follow step by step the modifications resulting from peripheral nerve section. This characteristic makes the turtle an excellent model for the investigation of the anaerobic process, that may be common to all vertebrate brains, since the sequence of mammal changes occurs so rapidly that is difficult to follow it (20). However, it is possible that the difference between turtle and rat could be due to a lack of recovery in the turtle, since the observations did not continue beyond 90 days.

It is difficult, at this time, to say that the changes only resulted from primary afferent degeneration. Further experiments using electron microscopy and anterograde and retrograde tracers will be necessary. In addition, it is early to speculate whether the actions of substance $\mathrm{P}$ are similar in turtles and mammals, and it is evident that to understand the significance and real role of this neuropeptide in the turtle spinal cord, multiple approaches, including biochemical, cytochemical, other immunohistochemical, molecular and other physiological procedures will be necessary. However, the observations reported here suggest that the similarity is probable. Actually, interest in more simple, experimentally resistant biological material is increasing. Within this context, the turtle should not be ignored as a model for the study of substance $P$ actions and could offer new insights into nociception, since this neuropeptide is involved in the modulation of pain-related information in mammals.

\section{Acknowledgments}

We would like to thank Christiane de Queiroz Lopes and Eudira da Luz Amaral for technical assistance.
Figure 2. Absorbance of substance $\mathrm{P}$ immunoreactivity, obtained from synaptic subfield la. No statistical difference was found between the ipsilateral (ipsi) and contralateral (contra) sides in any of the groups studied (a $P$ value of 0.05 or less being considered significant). All statistical analyses were performed using the Student $t$-test and the SPSS 7.0 statistical package software. The results are reported as means \pm SD. 


\section{References}

1. Fields HL (1994). Peripheral neuropathic pain: An approach to management. In: Wall PD \& Melzack R (Editors), Textbook of Pain. Churchill Livingstone, New York, NY, USA.

2. Tessler A, Himes BT, Krieger NR, Murray M \& Goldberger ME (1985). Sciatic nerve transection produces death of dorsal root ganglion cells and reversible loss of substance $P$ in spinal cord. Brain Research, 332: 209-218.

3. Wang SD, Goldberger ME \& Murray M (1991). Plasticity of spinal systems after unilateral lumbosacral dorsal rhizotomy in the adult rat. Journal of Comparative Neurology, 304: 555-568.

4. Northcutt RG (1970). The Telencephalon of the Western Painted Turtle (Chrysemys picta bellis). University of Illinois Press, Urbana, Chicago, London.

5. Reiner A, Krause JE, Keyser KT, Eldred WD \& McKelvy JF (1984). The distribution of substance $P$ in turtle nervous system: A radioimmunoassay and immunohistochemical study. Journal of Comparative Neurology, 226: 50-75.

6. Luthman J, Fernández A, Radmilovich M \& Trujillo-Cenóz O (1991). Immunohistochemical studies on the spinal dorsal horn of the turtle Chrysemys d'orbigny. Tissue and Cell, 23: 515-523.

7. Belló AA \& Belló-Klein A (1991). A technique to anesthetize turtles with ether. Physiology and Behavior, 50: 847-848.

8. De Felipe MC, Molinero MT \& Del Río J (1989). Long-lasting neurochemical and functional changes in rats induced by neonatal administration of substance P antiserum. Brain Research, 485: 301-308.

9. Trujillo-Cenóz O, Fernández A \& Radmilovich M (1990). Fine structure and synaptic connections of the spinal dorsal root terminals in the turtle Chrysemys d'orbigny. Tissue and Cell, 22: 811-826.

10. Ljungdahl A, Hökfelt $T$ \& Nilsson G (1978). Distribution of substance P-like immunoreactivity in the central nervous system of the rat. I. Cell bodies and nerve terminals. Neuroscience, 3: 861-944.

11. De Ceballos ML, Jenner P \& Marsden CD (1999). Increased (met)enkephalin and decreased substance $P$ in spinal cord following thermal injury to one limb. Neuroscience, 36: 731-736.
12. Aronin N, Difiglia M \& Leeman SE (1983). Substance P. In: Krieger DT, Brownstein MJ \& Martin JB (Editors), Brain Peptides. Wiley, New York, NY, USA.

13. Inagaki S, Senba E, Shiosaka S, Takagi H, Kawai Y, Takatsuki K, Sakanaka M, Matsuzaki T \& Tohyama M (1981). Regional distribution of substance P-like immunoreactivity in the frog brain and spinal cord: Immunohistochemical analysis. Journal of Comparative Neurology, 201: 243-254.

14. Lorez HP \& Kemali M (1981). Substance P-, met-enkephalin- and somatostatin-like immunoreactivity distribution in the frog spinal cord. Neuroscience Letters, 26: 119-124.

15. Lavalley $A L \&$ Ho $R H$ (1983). Substance $P$, somatostatin, and methionine enkephalin immunoreactivity elements in the spinal cord of the domestic fowl, Gallus domesticus. Journal of Comparative Neurology, 213: 406-413.

16. Jessell T, Tsunoo A, Kanazawa I \& Otsuka M (1979). Substance P: Depletion in the dorsal horn of the rat spinal cord after section of the peripheral processes of primary sensory neurons. Brain Research, 168: 247-259

17. Murray M \& Goldberger ME (1986). Replacement of synaptic terminals in lamina II and Clarke's nucleus after unilateral lumbosacral dorsal rhizotomy in adult cats. Journal of Neuroscience, 16: 32053217.

18. Croul S, Svertink A, Radzievsky A \& Murray M (1995). Modulation of neurotransmitter receptors following unilateral L1-S2 deafferentation: NK1, NK3, NMDA, and 5HT1a receptor binding autoradiography. Journal of Comparative Neurology, 361: 633-644.

19. Zhang B, Goldberger ME \& Murray M (1993). Proliferation of SP and $5 \mathrm{HT}$ containing terminals in lamina II of rat spinal cord following dorsal rhizotomy: Quantitative EM-immunocytochemical studies. Experimental Neurology, 123: 51-64.

20. Lutz PL (1992). Mechanisms for anoxic survival in the vertebrate brain. Annual Review of Physiology, 54: 601-618. 